\title{
Three-month follow-up of Western and non-Western participants in a study on preconceptional ancestry- based carrier couple screening for cystic fibrosis and hemoglobinopathies in the Netherlands
}

Phillis Lakeman, MD ${ }^{1,2}$, Anne Marie C. Plass, PhD ${ }^{1,2}$, Lidewij Henneman, PhD ${ }^{2,3}$, Pieter D. Bezemer, PhD ${ }^{2,4}$, Martina C. Cornel, $M D, P h D^{1,2}$, and Leo P. ten Kate, $M D, P h D^{1,2}$

\begin{abstract}
Objective: To study psychological outcomes, knowledge, recall and understanding of test-results, satisfaction, and reproductive intentions among 97 Western and 46 non-Western participants in a unique preconceptional carrier screening study for both cystic fibrosis and hemoglobinopathies in a multiethnic population the Netherlands, in which a couple's eligibility for cystic fibrosis and/or hemoglobinopathies testing was based on both partners' ancestry. Methods: Questionnaires before and after pretest consultation, and 1 week and 3 months after receiving test-results. Three cystic fibrosis and seven hemoglobinopathy carriers were identified, but no carrier couples. Results: Overall, anxiety levels were low, knowledge improved after pretest consultation but decreased after 3 months. Ninety-four percent remembered their test-results. Western compared with non-Western participants had higher knowledge-scores and better understanding of test-results. None of the carriers felt less healthy, six felt relieved, and one felt disappointed. Four carriers were unaware of the residual risk of having an affected child. Participants intended to draw reproductive decisions from test-results, were satisfied, did not regret participation, and did not report major feelings of discrimination or stigmatization. Conclusions: Similar to previous studies, no major adverse psychological effects were demonstrated among the Western and non-Western participants in this study, and they would draw reproductive decisions on test-results. No arguments for rejecting a combined offer of preconceptional ancestry-based cystic fibrosis and hemoglobinopathies carrier screening were found. An extensive implementation study should be carried out, in which understanding of test-results needs further attention, to investigate whether or not this type of screening should be implemented on a large scale in the Netherlands. Genet
\end{abstract} Med 2008:10(11):820-830.

Key Words: preconceptional carrier screening, cystic fibrosis, hemoglobinopathies, knowledge, anxiety, understanding, satisfaction, ancestry, reproductive intentions, Western and Non-Western

Cystic fibrosis (CF) and hemoglobinopathies (HbPs), like sickle cell disease and thalassemia, are common serious autosomal recessive disorders, for which the risk of being a mutation carrier varies depending on a person's ancestry. $\mathrm{CF}$ is most common among Europeans and their descendants, with a carrier frequency of 1 in $20-30$ individuals, resulting in a 1 in 400-900 carrier couple frequency and a

\footnotetext{
From the ${ }^{1}$ Department of Clinical Genetics, ${ }^{2}$ EMGO Institute, Departments of ${ }^{3}$ Public and Occupational Health, and ${ }^{4}$ Clinical Epidemiology and Biostatistics, VU University Medical Center, Amsterdam, The Netherlands.

Phillis Lakeman, MD, Department of Clinical Genetics, EMGO Institute, VU University Medical Center, P.O. Box 7057, 1007 MB Amsterdam, The Netherlands. E-mail: p.lakeman@vumc.nl.

Disclosure: The authors declare no conflict of interest.

Submitted for publication February 23, 2008.

Accepted for publication July 31, 2008.
}

DOI: 10.1097/GIM.0b013e318188d04c
CF birth prevalence of 1 in $1600-3600 .^{1,2}$ HbPs are more common in people with ancestors from Africa, the Mediterranean area, the Middle East, parts of the Indian subcontinent, and South-East Asia, where carrier frequencies range from 5 to $40 \% .^{3-5}$ Because of the autosomal recessive inheritance pattern, most patients lack a family history of the disorder, and healthy carriers are usually unaware of their carrier status. Therefore, carrier couples generally do not know that they face a risk of $25 \%$ in each pregnancy of having an affected child.

Preconceptional carrier couple screening aims to benefit prospective parents. It enables carrier couples to make an informed reproductive decision before pregnancy, without the emotion and pressure associated with prenatal screening and with the availability of a maximum of reproductive options. ${ }^{1,6}$ These options not only include prenatal diagnosis followed (or not) by abortion or accepting the risk, but also deciding to refrain from having children, adoption, using donor sperm or 
eggs, and preimplantation genetic diagnosis. In some culturerelated marriage practices, it could possibly result in choosing a different partner.

Potential harmful effects of preconceptional carrier screening, such as inducing stress, anxiety, and excessive worrying, and also misunderstanding of the test-results should be avoided, as well as adverse social consequences, such as the stigmatization and discrimination of carriers. ${ }^{7-9}$ Multiple studies have demonstrated that both carriers and noncarriers may experience negative feelings, such as anxiety and worry, when participating in genetic screening, ${ }^{10-17}$ but anxiety levels often decrease after a few months. ${ }^{11,18-20}$ Some CF carriers even perceived themselves as less healthy, ${ }^{10,14}$ whereas others falsely believed that they were only likely to be carriers. ${ }^{10,11,14}$ Many couples in which only one partner had been identified as a carrier were unaware of their residual risk of having an affected child-a risk because of the limited sensitivity of the DNA testing. ${ }^{17,21,22}$ Correspondingly, it was found among those who tested negative, that they falsely believed that they were definitely not carriers, ${ }^{11,14}$ although they had been informed that the test-sensitivity was $<100 \%$.

In most (Northern) European countries, including the Netherlands, preconceptional screening for CF and HbPs is not current practice, despite the results of several pilot studies showing positive attitudes toward offering this kind of screening and positive intentions to participate in carrier screening for CF and HbPs. ${ }^{10,11,16,20,23-27}$ Targeted ancestry-based carrier screening has been advised, ${ }^{28-30}$ but at the same time concern has been expressed about the potential harm of ancestry-based screening because of negative experiences, such as the discrimination and stigmatization that occurred after the implementation of sickle cell screening in the United States in the early 1970s. ${ }^{8}$ An offer of combined targeted CF and HbPs carrier couple screening might, however, reduce the potential risk of stigmatization or discrimination of subpopulations, because almost every couple, irrespective of ancestry, will be eligible for some form of carrier screening: for CF, HbPs, or both disorders. Furthermore, a consumer-driven approach, in which couples by themselves assess the appropriate screening test(s) in their specific situation, is more preferable than a providerdriven approach. Selection on the basis of physical appearance, nationality, or analysis of names by the care-provider of government has proven to be subjective, imprecise, and unreliable. $^{31-33}$

In considering whether or not to implement routine ancestry-based preconceptional carrier screening for these disorders in general health care, it must first be clear whether or not the benefits outweigh the potential harms for both Western and non-Western prospective parents. ${ }^{34}$ Western people have their ancestry in Europe (including the Netherlands), North-America, and Australia, and those who originate from other parts of the world are defined as non-Western people including people from Turkey, Surinam, Morocco, and the Netherlands Antilles, who form the four largest immigrant groups in the Netherlands. ${ }^{35,36}$
The present study is part of a larger study-project in which preconceptional $\mathrm{CF}$ and/or HbPs carrier couple screening was offered to a multiethnic population in Amsterdam, the Netherlands. A previously validated decisional instrument was used to assess a couple's eligibility for $\mathrm{CF}$ and/or HbPs carrier screening. ${ }^{37}$ This instrument combined answers about both partners' ancestry and also took mixed ancestry into account. Couples of Western origin were mainly eligible for CF carrier screening and couples of non-Western origin for HbPs carrier screening. Couples from Turkey and Morocco were eligible for both the CF and the HbPs carrier screening tests. ${ }^{37}$

The present study aimed to investigate how the test-participants in this particular study had experienced their participation, and how this was compared with other more classical approaches to carrier screening. The following research questions were addressed: (1) How do participants in preconceptional ancestry-based CF and HbPs carrier screening experience their participation in terms of psychological outcomes? What is the extent of their knowledge on the inheritance of these disorders? Were participants able to recall and understand their test-results? What are their reproductive intentions? Were the participants satisfied with their test-participation? (2) Are there differences on these issues between Western and non-Western participants?

\section{MATERIALS AND METHODS}

\section{Participants and procedure}

Screening was offered to 9453 individuals (20-35 years), including 50-60\% non-Western immigrants, in Amsterdam from January to December 2005 (Fig. 1), by either the invitees' own general practitioner (GP), who selected names and addresses from the practice register or by the Municipal Health Service, who was provided with names and addresses from the population register. An information leaflet was enclosed with the invitation, which described clinical and genetic aspects of $\mathrm{CF}$ and HbPs, advantages and disadvantages of participation, the test procedure, and test-sensitivity. Invitees also received the above-mentioned decisional instrument to assess a couple's eligibility for $\mathrm{CF}$ and/or HbPs carrier screening ${ }^{37}$ and a reply form. All documents were available in Dutch only.

Invitees who had a partner with whom they were planning a pregnancy, irrespective of whether this would be in the near future or at a later date, were eligible for participation and are referred to as the target population. Exclusion criteria were pregnancy, inability to read and write Dutch, and a positive family history of CF and/or HbPs. In the latter situation, the couple was advised to contact a clinical geneticist for counseling. On the reply form, invitees could indicate whether or not they had a partner with whom they were planning a pregnancy, and whether or not one (or more) of the exclusion criteria applied. It was estimated that $33 \%(n=3120)$ of the 9453 individuals belonged to the target population. This estimation was based on (a) the reply forms of 1365 respondents ( $14 \%$ of the invitees) of whom 490 (36\%) belonged to the target population; and (b) a telephone survey among a random sample of 


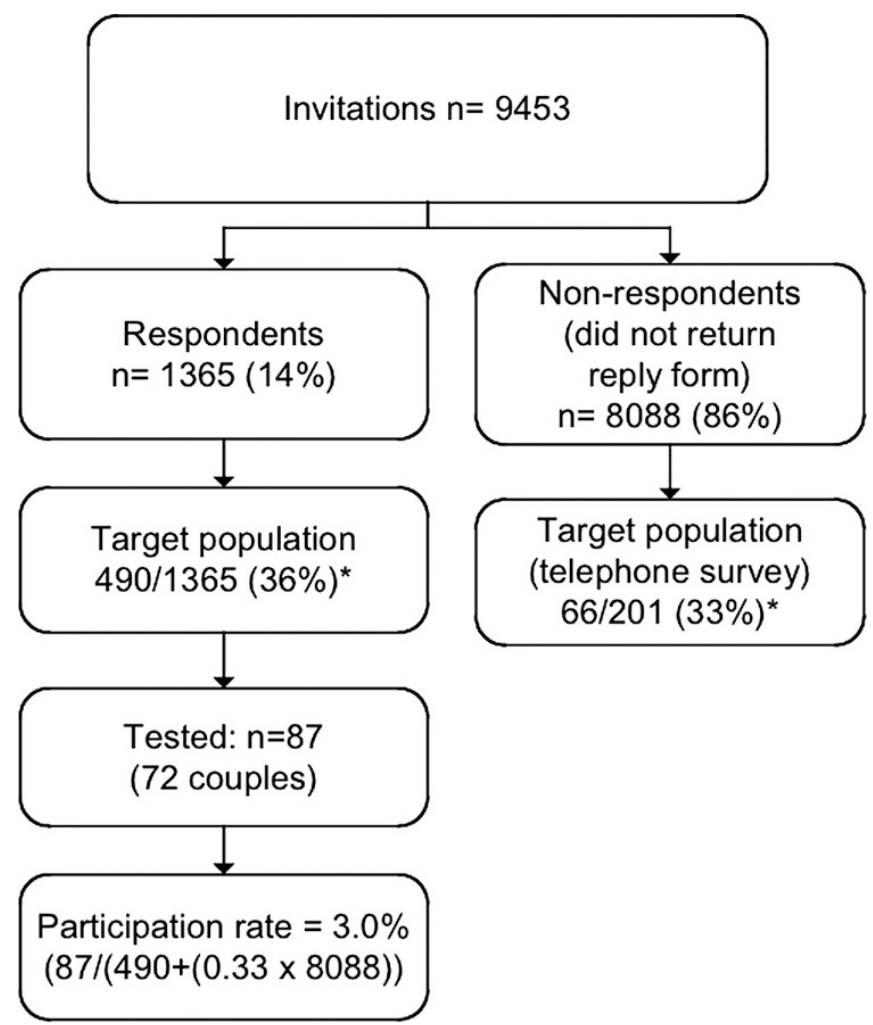

Fig. 1. Flowchart on recruitment of participants in the preconceptional CF and $\mathrm{HbPs}$ carrier screening study. Target population: invitees with a partner and who were considering a pregnancy with that partner. *The percentage of respondents who belonged to the target group was 36\% (490 of 1365; 95\% Cl 33-38\%) and was not statistically different from the proportion of $33 \%$ (66 of $201 ; 95 \% \mathrm{Cl}$ 26-39\%) among the nonrespondents $(P=0.054)$.

nonrespondents ( $n=201)$ of whom $66(33 \%)$ belonged to the target population. In total, 87 of the original invitees actually participated in the testing, providing a total of 72 couples (there were 15 couples in which both partners had received a personal invitation). Therefore, the participation rate among eligible invitees was $3 \%((87 /[490+(0.33 \times 8088)]$; $95 \%$ confidence interval [CI] 2.2-3.4\%)).

The participants, together with their partner, were required to visit their GP within 1 month for pretest consultation and sampling of both partners for the carrier tests (free of charge). Forty-seven couples were eligible for screening for CF only, 6 for HbPs only, and 19 for both disorders, based on the validated decisional instrument. ${ }^{37}$ Actual testing took place after receiving a signed informed consent form that had to be returned to the researcher (P.L.) within 1 week after sampling. It was explained that a positive test-result definitely identified a person as a carrier, but that a negative result did not definitely exclude the possibility of being a carrier.

The CF carrier testing was carried out step-wise: one partner was tested first and the second partner was tested only if the first partner's test-result was positive. For this study, we designed a CF transmembrane conductance regulator mutation panel, consisting of 33 CFTR mutations that have been identified on at least two unrelated alleles in Dutch and Turkish people. ${ }^{38,39}$ On the informed consent form, the couples could indicate who should be tested first. For the HbPs carrier testing, both partners were tested. Three CF carriers of Western origin and seven $\mathrm{HbP}$ carriers of non-Western origin were identified, but no carrier couples.

Test-results of both partners were sent by mail in one letter addressed to the couple, and the GP received a copy. Couples in whom one partner was identified as a carrier, and the other tested negative, were informed about the residual risk of having an affected child. It was emphasized to people with a negative test-result that there still might be a small risk of being a carrier and a (small) residual risk of having an affected child. Carrier couples, if identified, would have been invited for counseling at a Clinical Genetics Service. The study protocol of the project was approved by the Medical Ethics Committee of the VU University Medical Center in Amsterdam.

\section{Questionnaires}

The participants were asked to complete individually a structured questionnaire at four different measurement moments during the study: about 30 minutes before the pretest consultation (Q1), within 1 week after the consultation (Q2), and 1 week (Q3) and 3 months (Q4) after receiving the testresults. Of the 72 participating couples, 143 test-participants were willing to complete the questionnaires. The outcome measures, their corresponding items, and the answer format that were included in the questionnaires are presented in Table 1 and include psychological outcome measures (i.e., anxiety and other emotional outcomes), knowledge about inheritance, recall and understanding of test-results (i.e., test-validity and consequences of test-results), reproductive intentions, and satisfaction. All participants, irrespective of their ancestry, were asked to complete all questions. In Q1, sociodemographic variables were assessed including gender, age, marital status, level of education, number of children, native country, and parental native country.

\section{Data-analyses}

In general, both partners in a couple were treated as independent subjects, because earlier research showed that individual partners provide different information. ${ }^{25,40}$ No statistical comparison of carriers and noncarriers was performed as only seven carriers completed all the questionnaires (Q1-Q4). Independent sample T-tests or ANOVA analyses were performed to compare the mean scores for the variables between groups at the same measurement moment. For each measurement moment, the total number of participants who completed that specific questionnaire were included in the analysis: Q1 $(n=$ $143), \mathrm{Q} 2(n=139), \mathrm{Q} 3(n=116)$, and Q4 $(n=120)$.

For longitudinal comparison of the mean scores for the variables at different measurement moments, we used dependent sample T-test(s) and General Linear Model-analysis for repeated measurements. In the analysis of these measurements, we included the total number of participants who completed all the questionnaires in which questions were asked about that specific variable. Not all variables were included in each questionnaire. Therefore, for each variable there were different to- 
Table 1

Outcome measures of the questionnaires Q1-Q4

\begin{tabular}{lll}
\hline Outcome measure & Questionnaire $^{a}$ & Statements/items/answer format \\
\hline
\end{tabular}

\section{Psychological outcomes}

Anxiety $^{b}$
Q1-Q4
I feel calm

I feel tense

I am confused

I am relaxed

I am satisfied

I am worried

I was worried while waiting for my test-results (only Q3)

I was worried after receiving the test-results

I perceive myself as less healthy after receiving the test-results

I feel relieved after receiving the test-results

I feel disappointed after receiving the test-results

Knowledge about inheritance ${ }^{d}$

Q1-Q3
A carrier of CF can also have CF (Yes, I agree/No, I do not agree/I don't know)

A carrier of sickle cell disease or thalassemia, can also have these disorders (Yes, I agree/No, I do not agree/I don't know)

It is possible to be a carrier of CF or HbPs when these disorders are not present in your family (Yes, I agree/No, I do not agree/I don't know)

When do parents have a high risk of having a child with CF or HbPs? (If both partners are carriers/If just one partner is a carrier/I don't know)

What is the chance of having an affected child when both partners are carriers? (100\%/50\%/25\%/I don't know)

Recall of test-results ${ }^{e}$

Q3-Q4

1. For which disorder were you and your partner eligible for testing? (for $C F$, for $\mathrm{HbPs}$, or for both disorders?)

2a. Participants in the CF carrier testing were asked to tick one option out of the following:

I was not identified as a CF carrier, and my partner has not been tested

My partner was not identified as a CF carrier, and I have not been tested

I am a CF carrier, but my partner is probably not

My partner is a CF carrier, but I am probably not

We are both CF carriers

I don't know

2b. Participants in the HbPs carrier testing were asked to tick one or more options out of the following:

I am a carrier of sickle cell disease

My partner is a carrier of sickle cell disease

I am a carrier of thalassemia

My partner is a carrier of thalassemia

Neither of us is a carrier of sickle cell disease

Neither of us is a carrier of thalassemia

I don't know

Understanding of test-results

Understanding of test-validity

Q2-Q3

A person with a positive test-result is definitely a carrier (Yes, I agree/No, I do not agree/I don't know) 
Table 1

Continued

\begin{tabular}{|c|c|c|}
\hline Outcome measure & Questionnaire $^{a}$ & Statements/items/answer format \\
\hline & & $\begin{array}{l}\text { A person with a negative test-result is definitely not a carrier (Yes, I agree/No, } \\
\text { I do not agree/I don't know) }\end{array}$ \\
\hline $\begin{array}{l}\text { Understanding of consequences of test-results } \\
\text { (residual risk })^{\text {e,f }}\end{array}$ & Q3-Q4 & $\begin{array}{l}\text { If you and your partner are planning to have children in the future, what is, } \\
\text { with your test-result, the risk of having a child with CF/sickle cell disease/ } \\
\text { thalassemia? (Very high risk/high risk/not a high risk, but also not a low risk/ } \\
\text { low risk/very low risk/no risk of having an affected child/I don't know) }\end{array}$ \\
\hline \multirow[t]{11}{*}{ Reproductive intentions ${ }^{g}$} & Q2 & I would not have (anymore) children if my partner and I were both carriers \\
\hline & & I would opt for prenatal diagnosis if my partner and I were both carriers \\
\hline & & I would consider termination of pregnancy if the unborn child was affected \\
\hline & Q4 & $\begin{array}{l}\text { Did the test-results change your ideas about having children? (Yes/No/I } \\
\text { don't know) }\end{array}$ \\
\hline & & If yes, they were asked to tick one option out of the following: \\
\hline & & I am surer about having children \\
\hline & & I now have doubts about having (more) children \\
\hline & & I want more children than I did before the carrier testing \\
\hline & & I want less children than I did before the carrier testing \\
\hline & & I now definitely don't want (more) children \\
\hline & & My ideas have changed in other ways \\
\hline
\end{tabular}

Satisfaction $^{8}$

Q3-Q4

If I had to decide again, I would participate again

I would recommend the screening to other couples if this was a possibility

I regret the fact that I participated in the screening

${ }^{a} \mathrm{Q} 1: 30$ minutes before pretest consultation, Q2: within 1 week after the consultation, Q3: 1 week after receiving the test-results, Q4: 3 months after receiving the test-results.

${ }^{b}$ Anxiety was assessed on a 4-point scale with the 6-item short form of the state scale of the Spielberger Stait-Trait Anxiety Inventory (STAI): a score of 1 indicated a low level of anxiety, and a score of 4 indicated a high level of anxiety. Items were recoded into the same direction if necessary.

${ }^{c}$ Items were measured on a 5-point Likert-scale ranging from fully disagree (1) to fully agree (5).

${ }^{d}$ The number of correct answers was calculated as a sum-score, with a maximum of 5 .

${ }^{e}$ One of the researchers (P.L.) scored the answers as correct or incorrect by comparing them with the actual test-results.

fParticipants only completed this question for the disorder(s) for which they had been tested. As there were no carrier couples, "low risk" and "very low risk" were assessed as the correct answers.

${ }^{8}$ Items were measured on a 5-point Likert-scale ranging from fully disagree (1) to fully agree (5), and were recoded where necessary: a score of 1 indicated a negative/unfavorable score, and a score of 5 indicated a positive/favorable score.

tal numbers of participants, which could be included in the analyses for repeated measurements. Furthermore, we analyzed whether or not the variables differed between Western and non-Western participants and if so, whether or not this difference was (co-)determined by other sociodemographic variables.

In addition, for each variable we calculated the proportion of Western and non-Western participants who had a score below and/or above 3 (the neutral point). The $\chi^{2}$ test was used for the statistical comparison of proportions. All analyses were performed in SPSS 14.0 (SPSS Inc., Chicago, IL) for Windows.

\section{RESULTS}

\section{Response}

Q1 was returned by $100 \%$ of the participants $(n=143)$, Q2 by $97 \%$ ( 139 of 143 ), Q3 by $81 \%$ (116 of 143) including 7 of the 10 carriers, and Q4 was returned by $84 \%$ (120 of 143) including nine carriers. In total, 110 participants completed all questionnaires (Q1-Q4), resulting in a response of 77\% (103 of 133) among the noncarriers and 70\% (7 of 10; three CF and four $\mathrm{HbP}$ carriers) among the carriers. In most cases there was no information about the reasons for the loss to follow-up, but some participants stated that they just did not feel like participating anymore. In total, $68 \%$ (97 of 143) of the participants were of Western origin: indigenous Dutch $(n=83)$ and other European origin $(n=14) ; 32 \%$ (46 of 143 ) were of non-Western origin: from South-East Asia $(n=15)$, Turkey $(n=14)$, Morocco $(n=5)$, other North African Countries $(n=7)$, Surinam $(n=3)$, the Middle East $(n=1)$ and South America $(n=1)$.

The sociodemographic characteristics of the 143 participants are presented in Table 2. The non-Western compared with the Western participants had a significantly lower level of education and significantly more of them were married and already had children. 
Table 2

Sociodemographic characteristics of Western and non-Western participants in the screening test(s)

\begin{tabular}{lccc}
\hline & \multicolumn{2}{c}{ Participants $^{a}$} & \\
\cline { 2 - 3 } & $\begin{array}{c}\text { Western } \\
\text { origin }\end{array}$ & $\begin{array}{c}\text { Non-Western } \\
\text { origin }\end{array}$ & Total \\
\hline Individuals, $n$ & 97 & 46 & 143 \\
Men, $n(\%)$ & $46(47)$ & $25(54)$ & $71(50)$ \\
Women, $n(\%)$ & $51(53)$ & $21(46)$ & $72(50)$ \\
Age, mean (range) & & & \\
$\quad$ Men & $32(23-47)$ & $31(23-47)$ & $32(23-47)$ \\
$\quad$ Women & $30(19-41)$ & $27(20-35)^{c}$ & $29(19-41)$ \\
Married, $n(\%)$ & $20(21)$ & $30(65)^{d}$ & $50(35)$ \\
With children, $n(\%)$ & $15(16)$ & $19(41)^{d}$ & $34(24)$ \\
Level of education, $n(\%)^{b}$ & & & \\
$\quad$ Low & $4(4)$ & $11(24)^{d}$ & $15(11)$ \\
Intermediate & $37(38)$ & $25(54)^{c}$ & $62(43)$ \\
High & $56(58)$ & $10(22)^{d}$ & $66(46)$ \\
\hline
\end{tabular}

${ }^{a}$ Definition of Western origin, including the indigenous Dutch people $(n=$ 83) and of non-Western origin as defined by Statistics Netherlands. ${ }^{35}$

${ }^{b}$ Low: primary school, lower level of secondary school, lower vocational training. Intermediate: higher level of secondary school, intermediate vocational training. High: higher vocational training, university.

${ }^{c} P<0.05 ;{ }^{d} P<0.001$. Difference between Western and non-Western participants.

\section{Psychological outcomes}

The participants who completed all four questionnaires $(n=110)$ reported a low level of anxiety at the start, which decreased further during the study $(P=0.001)$ : the mean scores at Q1, Q2, Q3, and Q4 were $\mathrm{M}=1.6,1.5,1.3$, and 1.3, respectively. These scores did not clearly differ from the levels of anxiety among the total number of $143,139,116$, and 120 participants who completed Q1, Q2, Q3, and Q4, respectively. Furthermore, those participants $(n=33)$ who had been (partially) lost to follow-up after Q1 were not more anxious at Q1 than those who completed all questionnaires $(n=110)$ : their mean levels of anxiety at Q1 were $\mathrm{M}=1.8$ and 1.6 , respectively $(P=0.1)$. Among the carriers, two felt anxious 1 week after receiving the test-results $(\mathrm{Q} 3)$, and one was still anxious at the 3-month follow-up (Q4). The majority of participants (73\%; 85 of 116) reported that they had not been worried (score $\leq 3$ ) while waiting for their test-results $(M=2.1)$.

None of the participants, including the carriers, perceived themselves as being less healthy after receiving the test-results (Q3 and Q4). Further, 68\% (79 of 116) and 62\% (74 of 120) felt relieved (score > 3) at Q3 $(\mathrm{M}=3.6)$ and $\mathrm{Q} 4(\mathrm{M}=3.5)$, respectively, including seven and six carriers. Among those who did not feel relieved, there were six and seven partners of carriers at Q3 and Q4, respectively. Four participants, including two carriers, were disappointed (score $>3$ ) 1 week after receiving the results $(\mathrm{Q} 3)$, but none of them were disappointed at the 3-month follow-up (Q4). However, four other participants reported feelings of disappointment at Q4, including two negative-tested partners of CF carriers.

\section{Knowledge}

Table 3 shows the proportion of participants with a high level of knowledge (sum-score $>2.5$ ) and the mean knowledge scores of the participants who completed Q1-Q3 $(n=116)$. In general, the knowledge scores significantly increased from before (Q1) to after the pretest consultation (Q2), but also significantly decreased when measured 1 week after receiving the test-results $(\mathrm{Q} 3)(P<0.001)$. Among those with a high level of knowledge at Q3, there were two carriers (out of seven who completed Q3) and three negative-tested partners.

\section{Recall and understanding of test-results}

In total, 93\% (108 of 116) and 94\% (113 of 120) of the participants were able to recall their test-results 1 week (Q3) and 3 months after receiving them (Q4). At Q4, seven participants, including two HbP carriers and their partners, did not know their test-results.

Table 4 presents the understanding of test-results based on (a) understanding of test-validity in general (assessed at Q2 and Q3), and (b) understanding of the consequences of their own test-results (assessed at Q3 and Q4). With regard to testvalidity in general, the meaning of a positive test-result (i.e., the person who tested positive is definitely a carrier) was better understood than the meaning of a negative test-result (i.e., the

Table 3

Proportion of Western and non-Western participants $(n=116)$ with high knowledge sum-scores $(>2.5)$ at different assessment moments during the study (Q1-Q3)

\begin{tabular}{|c|c|c|c|c|c|c|}
\hline \multirow[b]{3}{*}{ Knowledge sum-score $>2.5^{b}$} & \multicolumn{4}{|c|}{ Participants' origin } & & \\
\hline & \multicolumn{2}{|c|}{ Western $(n=82)$} & \multicolumn{2}{|c|}{ Non-Western $(n=34)$} & \multicolumn{2}{|c|}{ All $(n=116)$} \\
\hline & $n(\%)$ & Mean & $n(\%)$ & Mean & $n(\%)$ & Mean \\
\hline Q1: Before pretest consultation & $52(68)$ & 3.1 & $15(44)$ & $2.4^{a}$ & $67(58)$ & 2.8 \\
\hline Q2: Within 1 week after pretest Consultation & $66(81)$ & 3.7 & $23(68)$ & 3.4 & $89(77)$ & $3.7^{c}$ \\
\hline Q3: 1 week after receiving test-results & $54(66)$ & 2.9 & $15(44)$ & $2.5^{a}$ & $69(59)$ & 2.8 \\
\hline
\end{tabular}

${ }^{a} P<0.05$ : comparing Western and non-Western participants.

${ }^{b}$ Knowledge about inheritance of the disorders was calculated as a sum-score, with a minimum of 0 and a maximum of 5 .

${ }^{c} P<0.001$ : among all participants between Q1 and Q2 a significant increase occurred and between Q2 and Q3 knowledge decreased significantly. 
Table 4

Understanding of test-validity and understanding of consequences of own test-results among Western and non-Western participants

\begin{tabular}{|c|c|c|c|}
\hline & \multicolumn{2}{|c|}{ Origin of participants: } & \multirow[b]{2}{*}{ All $(n=116)$} \\
\hline & Western $(n=82)$ & Non-Western $(n=34)$ & \\
\hline \multicolumn{4}{|c|}{ Correct understanding of positive (unfavourable) test-result, $n(\%)$} \\
\hline After consultation-Q2 & $63(77)$ & $20(59)^{a}$ & $83(72)$ \\
\hline 1 week after test-results-Q3 & $52(63)$ & $18(53)$ & $70(60)^{b}$ \\
\hline \multicolumn{4}{|c|}{ Correct understanding of negative (favourable) test-result, $n(\%)$} \\
\hline After consultation-Q2 & $31(38)$ & $8(24)$ & $39(34)$ \\
\hline 1 week after receiving the test-results-Q3 & $41(51)$ & $15(44)$ & $56(48)^{c}$ \\
\hline \multicolumn{4}{|l|}{ Correct understanding of own test-results, } \\
\hline 1 week after receiving the test-results- $\mathrm{Q} 3$ & $47(55)$ & $14(41)$ & $61(53)$ \\
\hline At the 3-mo follow-up-Q4 & $36(42)$ & $9(26)^{a}$ & $45(39)^{d}$ \\
\hline
\end{tabular}

${ }^{a} P<0.05$ : difference between Western and non-Western participants.

${ }^{b} \mathrm{P}<0.05$ : difference between Q2 and Q3.

${ }^{c} P<0.001$ : difference between $\mathrm{Q} 2$ and Q3.

${ }^{d} P<0.001$ : difference between $\mathrm{Q} 3$ and $\mathrm{Q} 4$

person who tested negative has a residual risk of being a carrier): these questions were answered correctly $66 \%$ ( 153 of $232 ; 95 \%$ CI $60-72 \%$ ) of the times versus $41 \%$ ( 95 of $232 ; 95 \%$ CI $35-47 \%$ ) of the times, respectively $(P<0.001)$ (Table 4$)$. The meaning of a positive test-result was better understood after the pretest consultation (Q2) $(P=0.03)$, and the meaning of a negative test-result was better understood 1 week after receiving the results $(\mathrm{Q} 3)(P<$ $0.001)$. In addition, three carriers and four negative-tested partners thought that a person who tested negative had no residual risk of being a carrier or stated "I don't know."

The proportion of participants who correctly understood their own residual risk of having an affected child decreased significantly from the measurement 1 week after receiving the test-results (Q3) compared with the measurement at the 3-month follow-up (Q4): 53\% versus 39\%, respectively ( $P<$ 0.001 ). Four carriers and five negative-tested partners thought that there was no residual risk of having an affected child.

\section{Reproductive intentions}

No carrier couples had been identified. If they had turned out to be a carrier couple, $27 \%$ (37 of 139) of the participants stated that they would have considered not having (more) children. In case of a pregnancy, 89\% (124 of 139) would have opted for prenatal diagnosis, and 68\% (84 of 124) would consider an abortion if they were expecting an affected child. At the 3-month follow-up, $93 \%$ (112 of 120) of all participants, including all carriers, stated that the test-results had not changed their ideas about having children, $5 \%$ (6 of 120) of the participants, who all tested negative, stated that they now were surer about having children. A pregnancy was reported in $26 \%$ (19 of 72 ) of the couples.

\section{Satisfaction}

In general, the participants were satisfied with their participation (Table 5): 91\% stated that they would participate again, if they had to decide again, including the four participants who felt worried at the 3-month follow-up and eight of the nine carriers; $75 \%$ would recommend the screening to others; and no one regretted their participation with no difference between Q3 and Q4.

\section{Western versus non-Western participants}

Western compared with non-Western participants generally reported lower levels of anxiety (Fig. 2$)(P<0.001)$. NonWestern participants, compared with those of Western origin, were almost significantly more often worried while waiting for

Table 5

Satisfaction with participation in the screening at the 3-month follow-up (Q4)

\begin{tabular}{|c|c|c|c|c|c|c|}
\hline \multirow[b]{3}{*}{ Statements ${ }^{a}$} & \multicolumn{4}{|c|}{ Origin of participants: } & & \\
\hline & \multicolumn{2}{|c|}{ Western $(n=86)$} & \multicolumn{2}{|c|}{ Non-Western $(n=34)$} & \multicolumn{2}{|c|}{ All $(n=120)$} \\
\hline & $n(\%)$ & Mean & $n(\%)$ & Mean & $n(\mathrm{n} \%)$ & Mean \\
\hline I would participate again & $80(93)$ & 4.8 & $29(85)$ & 4.7 & $109(91)$ & 4.7 \\
\hline I would recommend testing to others & $64(74)$ & 4.3 & $26(77)$ & 4.5 & $90(75)$ & 4.3 \\
\hline I regret having participated & $0(0)$ & 1.1 & $0(0)$ & 1.0 & $0(0)$ & 1.0 \\
\hline
\end{tabular}

${ }^{a}$ Statements were measured on a 5-point Likert scale. Presented are the numbers and proportion of participants who had a score $>3$ for these items, as well as the mean scores. 


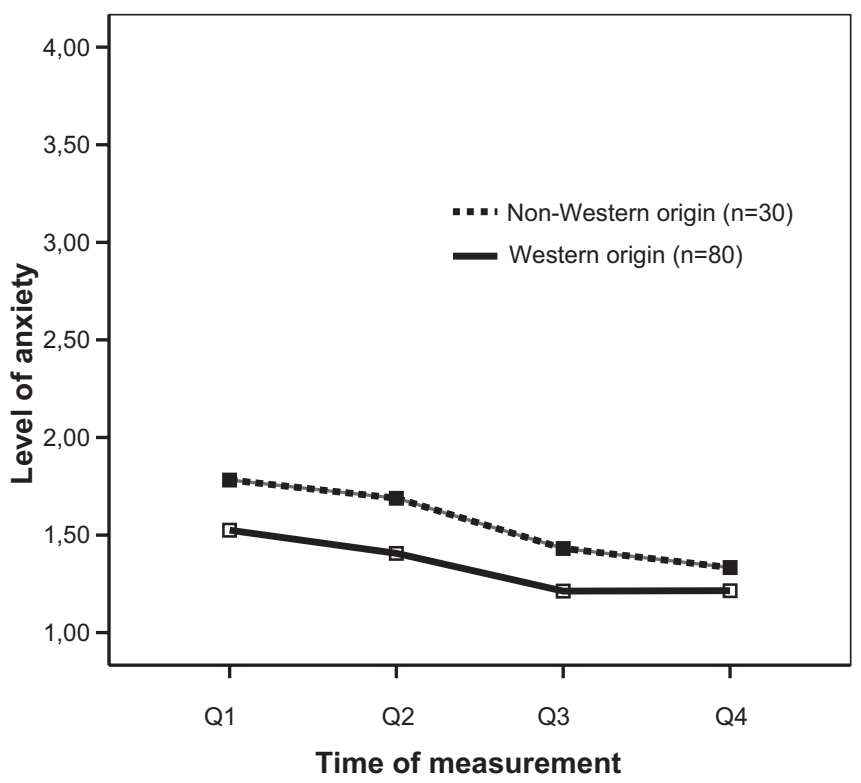

Fig. 2. Level of anxiety (assessed by using the 6-item short form of the State-Trait Anxiety Inventory [STAI] $)^{51,52}$ during the study among 110 test-participants who completed all questionnaires (Q1-Q4). Participants were asked to complete individually a structured questionnaire at four different moments in the study: 30 minutes before the pretest consultation (Q1), within 1 week after the pretest consultation (Q2), and 1 week (Q3) and 3 months (Q4) after receiving the test-results.

the test-results: $38 \%$ (13 of 34$)$ and $22 \%$ (18 of 82 ) had a mean score above $3(P=0.06)$; had lower mean knowledge scores before the pretest consultation $(\mathrm{Q} 1)$ and 1 week after receiving the test-results (Q3) $(P<0.05)$ (Table 3), which was mainly explained by a difference in level of education $(P=0.003)$; more often failed to recall their test-results at the 3-month follow-up (Q4): 18\% (6 of 34) versus 1\% (1 of 86) $(P=0.002)$; had less understanding of the test-validity with regard to the meaning of a positive test-result directly after the pretest consultation (Q2) $(P=0.044)$; more often misunderstood their residual risk of having an affected child: 73\% versus 58\% $(P<$ 0.001 ) (Table 4), and less frequently would consider an abortion if the fetus was affected: 49\% (22 of 45) versus 66\% (62 of 94) $(P=0.041)$. There were no differences in the frequency of feelings of relief or disappointment or in satisfaction.

\section{DISCUSSION}

Psychological outcomes, knowledge, recall and understanding of test-results, satisfaction, and reproductive intentions were studied among 97 Western and 46 non-Western participants in a unique study, carried out in the Netherlands, in which a combined offer of preconceptional carrier couple screening for both CF and HbPs was made in a specific multiethnic population, and in which a unique targeted ancestrybased approach was carried out to assess a couple's eligibility for CF and/or HbPs testing. In this study, invitees were provided with an information leaflet enclosed to the letter of invitation, those who had a partner with whom they were planning a pregnancy belonged to the target population, and partici- pants had to visit their GP for pretest consultation, where they also received a detailed brochure. Testing took place after receiving a signed informed consent form. The test-uptake among the eligible invitees was 3\%. Nevertheless, the large majority of 247 test nonparticipants had a positive attitude toward test-participation, and $68 \%$ of them would participate in the future if this kind of screening would be offered routinely (Lakeman et al., unpublished data). Practical barriers in terms of time and effort needed for participation were important factors of declining current test-participation (Lakeman et al., unpublished data).

In this unique study, we found, similar to the findings of other studies, ${ }^{10,11,16,19,20,41,42}$ no major adverse psychological effects. Overall, levels of anxiety were low, the majority of the participants had not been worried while waiting for the testresults, and only two remained worried after receiving the testresults. Furthermore, as reported before, ${ }^{11,41-44}$ but in contrast to others, ${ }^{10,14,45}$ none of the carriers perceived themselves as less healthy. The increase in anxiety reported among carriers in other studies after receiving the test-results, ${ }^{11,18-20}$ was absent in the present study. This might be due to the fact that both partners in a couple received their results simultaneously, and that all partners of carriers tested negative or it could simply be due to the relatively low number of participants. Nevertheless, we conclude that an offer of combined preconceptional ancestry-based CF and HbPs carrier couple screening does not cause major negative psychological harm, which is one of the prerequisites of offering genetic screening according to the genetic screening criteria. ${ }^{46}$

With regard to knowledge and understanding of the testresults, the results of the present study showed no major difference from those of previous studies either. Knowledge improved significantly from before to just after the pretest consultation. However, this increase in knowledge was not sustained, a finding that also was reported previously, ${ }^{11,14,42}$ whereas others reported no (major) decline in knowledge. ${ }^{20,44,47}$

Marteau et al. ${ }^{33}$ stated that besides having a positive attitude toward participation, sufficient knowledge, defined as 50\% or more correctly answered knowledge-questions, is one of the prerequisites for making an informed decision to participate or not in screening. The majority of the test-participants in the present study had a high knowledge score (a score $\geq 2.5$ out of a maximum 5) at the moment they decided to participate in the screening and based on Marteau's definition made an informed decision to participate in the carrier screening.

Furthermore, similar to the results of other studies, ${ }^{14,17,41,42,48}$ the large majority of the participants could recall their test-results. However, with regard to understanding the test-results, similarly to previous studies, ${ }^{10,41,42}$ almost half of the participants in the present study who tested negative erroneously believed that they were certainly no carriers, and almost half of the carriers thought that there was no residual risk of having an affected child. Not being aware of the limitations of DNA testing might confront some carriers who tested negative with the consequences of false reassurance, because car- 
riers still have a small risk of having an affected child. ${ }^{11,41}$ However, the risk is considerably smaller than if they had not participated in the screening.

Similar to the results reported previously, ${ }^{14,41}$ the participants in the present study were satisfied with their participation and would draw reproductive consequences from the testresults if they turned out to be a carrier couple: $27 \%$ would refrain from having more children; and in the case of pregnancy, $89 \%$ would opt for prenatal diagnosis, and $68 \%$ would consider an abortion if expecting an affected child. Therefore, this preconceptional screening program for $\mathrm{CF}$ and $\mathrm{HbPs}$ meets its general aim of facilitating informed reproductive decision-making among the participants. Although termination of a pregnancy was acceptable, knowledge about carrier status in general also seemed to limit plans to have more children. ${ }^{16,49}$ However, Poppelaars et al. ${ }^{50}$ reported that $21 \%$ of 380 recently married participants in a survey focusing on preconceptional CF carrier screening did not intend to change their reproductive plans, and that $54 \%$ were against the abortion of a child with CF. Married couples, however, may not be representative of all couples who are planning to have children in the Netherlands.

\section{Western versus non-Western participants}

In the present study, it was possible to focus on both Western and non-Western participants, who in general reported no adverse psychological outcomes, were satisfied with the screening, and intended to draw reproductive decisions from test-results. No feelings of stigmatization or discrimination were reported as well (Lakeman et al., unpublished data), suggesting that a combined ancestry-based offer to the whole population might be a solution to exclude or diminish feelings of this kind.

Non-Western participants had low, but higher levels of anxiety than the Western participants. They might have felt that they were more at risk, resulting in a slightly higher level of anxiety, because most non-Western participants were eligible for carrier screening for two disorders ( $\mathrm{CF}$ and $\mathrm{HbPs}$ ), whereas the Western participants were eligible for screening for "only" one disorder. It is also possible that the non-Western participants had a different interpretation of the six items of the short form of the Spielberger State-Trait Anxiety Inventory, which has not been validated among a large group of non-Western people. ${ }^{51,52}$ However, the reliability analysis that we performed showed Cronbach's $\alpha$ of above 0.7 .

Furthermore, non-Western participants, including four carriers, were more often unaware of the residual risk of having an affected child. This might be due to misunderstandings about inheritance of the disorders, because the non-Western participants had a significantly lower knowledge score, which was, in turn, related to the fact that the non-Western participants had a lower level of education.

Non-Western participants were less likely to consider the abortion of an affected fetus. However, Giordano et al..$^{53}$ reported a generally positive attitude among 328 pregnant immigrants in the Netherlands toward prenatal diagnosis and selec- tive abortion in the case of an $\mathrm{HbP}$-affected child, a finding that has also been reported by others outside the Netherlands. ${ }^{49,54,55}$

\section{Limitations of the study}

The present study has some limitations. The total number of participants is quite small resulting in a limited power to generalize the results. Furthermore, the study was conducted in a specific multiethnic population in Amsterdam, the Netherlands. The results might therefore be different if the study were conducted in other parts of the Netherlands and/or other countries. Furthermore, the written material was available in Dutch only. Although the majority of the nonindigenous invitees belonged to the second or third generation of immigrants (Statistics Netherlands) ${ }^{35}$ and were expected to be able to read and write Dutch, a limited command of the Dutch language could still have contributed to the under-representation of non-Western immigrants among the test-participants and might also have contributed to the small differences that were found between Western and non-Western participants.

Furthermore, we have limited information about the reasons for loss to follow-up. Although the 33 participants who had been (partially) lost to follow-up had a low level of anxiety at Q1 which did not differ significantly from those who completed all questionnaires, theoretically, those participants who had been lost to follow-up, might have become more anxious subsequently than those who completed all questionnaires. In addition, we had no control over the quality of the actual information the GPs gave to the participants. Finally, only 10 carriers and no carrier couples were identified.

\section{Recommendations}

The results of the present study, like previous studies, showed that there is a need for improving understanding of test-results. We suggest the following recommendations to achieve this goal. First, providing the results and offering the possibility of counseling by letter only may be insufficient. Carriers could also be proactively contacted with the offer of posttest consultations, ${ }^{48}$ in which the results can be repeated and the consequences for the carriers and for their relatives can be more clearly explained. ${ }^{56}$ However, Gordon et al..$^{42}$ found that the degree of understanding of the test-results in the longer term did not differ significantly between those who accepted an offer for posttest consultation and those who did not. Nevertheless, if counseling is offered, it should be available in the participants' own language. ${ }^{41,55}$ Second, translated copies of the information leaflet, the decisional instrument, and family letters should be made available. Third, storing test-results should be considered, for example in the GP's medical filing system or in patient files in a future general preconception consultancy setting. Fourth, genetic screening programs must include educational components as well. ${ }^{26,57,58}$ Not only the target population, but also GPs, obstetricians, and gynecologists should be educated with regard to the screening procedure and inheritance patterns. ${ }^{59}$ And it should be considered to educate the general population too about genetic risks and 
genetic tests (school education programs, leaflets, mass media campaigns, the Internet). This education will be important in increasing public knowledge and in shaping attitudes toward genetic testing. ${ }^{56-58,60}$

\section{CONCLUSION}

This report discusses the results of a unique combined study of preconceptional carrier screening for both CF and HbPs. This study was performed in a specific multiethnic population in the Netherlands, and the eligibility of participant couples for the CF and/or HbPs carrier testing was based on both partners' ancestral background. In this specific multiethnic setting and with this targeted ancestry-based approach, it was generally demonstrated, similar to the results of previous studies, that there were no major adverse psychological effects among both the Western and non-Western participants, that they were satisfied with the screening, and that they would base reproductive decisions on the test-results. In our opinion, therefore, there are no arguments for rejecting an offer of preconceptional ancestry-based CF and HbPs carrier couple screening. An extensive implementation study should be carried out, in which understanding of test-results needs further attention, to investigate whether or not this type of screening should be implemented on a large scale in the Netherlands, for example within the context of a general preconception care setting, as recently suggested by the Health Council of the Netherlands. ${ }^{61}$

\section{References}

1. Committee on Genetics, American College of Obstetricians and Gynecologists. ACOG Committee Opinion. Number 325, December 2005. Update on carrier screening for cystic fibrosis. Obstet Gynecol 2005;106:1465-1468.

2. Gilbert F. Cystic fibrosis carrier screening: steps in the development of a mutation panel. Genet Test 2001;5:223-227.

3. Angastiniotis M, Modell B. Global epidemiology of hemoglobin disorders. Ann NY Acad Sci 1998;850:251-269.

4. Modell B, Darlison M, Birgens H, et al. Epidemiology of haemoglobin disorders in Europe: an overview. Scand J Clin Lab Invest 2007;67:39-69.

5. Weatherall DJ, Clegg JB. Inherited haemoglobin disorders: an increasing global health problem. Bull World Health Organ 2001;79:704-712.

6. Raeburn JA. Screening for carriers of cystic fibrosis. Screening before pregnancy is needed. BMJ 1994;309:1428-1429.

7. Kenen RH, Schmidt RM. Stigmatization of carrier status: social implications of heterozygote genetic screening programs. Am J Public Health 1978;68:1116-1120.

8. Markel H. The stigma of disease: implications of genetic screening. Am J Med 1992; 93:209-215.

9. McQueen MJ. Some ethical and design challenges of screening programs and screening tests. Clin Chim Acta 2002;315:41-48.

10. Axworthy D, Brock DJ, Bobrow M, Marteau TM. Psychological impact of population-based carrier testing for cystic fibrosis: 3-year follow-up. UK Cystic Fibrosis Follow-Up Study Group. Lancet 1996;347:1443-1446.

11. Bekker H, Denniss G, Modell M, Bobrow M, Marteau T. The impact of population based screening for carriers of cystic fibrosis. J Med Genet 1994;31:364-368.

12. Gason AA, Sheffield E, Bankier A, et al. Evaluation of a Tay-Sachs disease screening program. Clin Genet 2003;63:386-392.

13. Hegwer G, Fairley C, Charrow J, Ormond KE. Knowledge and attitudes toward a free education and Ashkenazi Jewish carrier testing program. J Genet Couns 2006;15:61-70.

14. Henneman L, Bramsen I, Van der Ploeg HM, Ten Kate LP. Preconception cystic fibrosis carrier couple screening: impact, understanding, and satisfaction. Genet Test 2002;6:195-202.

15. Marteau TM. Psychological implications of genetic screening. Birth Defects Orig Artic Ser 1992;28:185-190.

16. Payne $\mathrm{Y}$, Williams $\mathrm{M}$, Cheadle J, et al. Carrier screening for cystic fibrosis in primary care: evaluation of a project in South Wales. The South Wales Cystic Fibrosis Carrier Screening Research Team. Clin Genet 1997;51:153-163.

17. Watson EK, Mayall ES, Lamb J, Chapple J, Williamson R. Psychological and social consequences of community carrier screening programme for cystic fibrosis. Lancet 1992;340:217-220.

18. Callanan NP, Cheuvront BJ, Sorenson JR. CF carrier testing in a high risk population: anxiety, risk perceptions, and reproductive plans of carrier by "non-carrier" couples. Genet Med 1999;1:323-327.

19. Honnor M, Zubrick SR, Walpole I, Bower C, Goldblatt J Population screening for cystic fibrosis in Western Australia: community response. Am J Med Genet 2000;93: $198-204$.

20. Watson EK, Mayall E, Chapple J, et al. Screening for carriers of cystic fibrosis through primary health care services. BMJ 1991;303:504-507.

21. Clausen H, Brandt NJ, Schwartz M, Skovby F. Psychological impact of carrier screening for cystic fibrosis among pregnant women. Eur J Hum Genet 1996;4:120-123.

22. Loader S, Caldwell P, Kozyra A, et al. Cystic fibrosis carrier population screening in the primary care setting. Am J Hum Genet 1996;59:234-247.

23. Bekker H, Modell M, Denniss G, et al. Uptake of cystic fibrosis testing in primary care: supply push or demand pull? BMJ 1993;306:1584-1586.

24. Giordano PC, Plancke A, Van Meir CA, et al. Carrier diagnostics and prevention of hemoglobinopathies in early pregnancy in The Netherlands: a pilot study. Prenat Diagn 2006;26:719-724.

25. Henneman L, Bramsen I, Van der Ploeg HM, et al. Participation in preconceptional carrier couple screening: characteristics, attitudes, and knowledge of both partners. J Med Genet 2001;38:695-703.

26. Poppelaars FA, Van der Wal G, Braspenning JC, et al. Possibilities and barriers in the implementation of a preconceptional screening programme for cystic fibrosis carriers: a focus group study. Public Health 2003;117:396-403.

27. Tambor ES, Bernhardt BA, Chase GA, et al. Offering cystic fibrosis carrier screening to an HMO population: factors associated with utilization. Am J Hum Genet 1994; 55:626-637.

28. ACOG (American College of Obstetricians and Gynecologists). Committee on Genetics. Committee opinion. Genetic screening for hemoglobinopathies, number 238, July 2000. Int J Gynaecol Obstet 2001;74:309-310.

29. European Society of Human Genetics. Population genetic screening programmes: technical, social and ethical issues. Eur J Hum Genet 2003;11(suppl 2):S5-S7.

30. Grody WW, Cutting GR, Klinger KW, Richards CS, Watson MS, Desnick RJ. Laboratory standards and guidelines for population-based cystic fibrosis carrier screening. Genet Med 2001;3:149-154.

31. Bouwhuis CB, Moll HA. Determination of ethnicity in children in The Netherlands: two methods compared. Eur J Epidemiol 2003;18:385-388.

32. Cummins C, Winter H, Cheng KK, Maric R, Silcocks P, Varghese C. An assessment of the Nam Pehchan computer program for the identification of names of south Asian ethnic origin. J Public Health Med 1999;21:401-406.

33. Marteau TM, Dormandy E, Michie S. A measure of informed choice. Health Expect 2001;4:99-108.

34. EUROGAPPP PROJECT 1999-2000 Public and Professional Policy Committee (PPPC). Population genetic screening programmes: Proposed recommendations of the European Society of Human Genetics. Eur J Hum Genet 2000;8:998-1000.

35. Statistics Netherlands. Voorburg/Heerlen, 2008. Available at: www.cbs.nl. Accessed May 11, 2008.

36. Stronks K, Ravelli AC, Reijneveld SA. Immigrants in the Netherlands: equal access for equal needs? J Epidemiol Community Health 2001;55:701-707.

37. Lakeman P, Henneman L, Bezemer PD, Cornel MC, Kate LP. Developing and op timizing a decisional instrument using self-reported ancestry for carrier screening in a multi-ethnic society. Genet Med 2006;8:502-509.

38. Bobadilla JL, Macek M Jr, Fine JP, Farrell PM. Cystic fibrosis: a worldwide analysis of CFTR mutations - correlation with incidence data and application to screening. Hum Mutat 2002;19:575-606.

39. Kilinç MO, Ninis VN, Dagli E, et al. Highest heterogeneity for cystic fibrosis: 36 mutations account for $75 \%$ of all CF chromosomes in Turkish patients. Am J Med Genet 2002;113:250-257.

40. Newman JE, Sorenson JR, DeVellis BM, Cheuvront B. Gender differences in psychosocial reactions to cystic fibrosis carrier testing. Am J Med Genet 2002; 113:151-157.

41. Denayer L, Welkenhuysen M, Evers-Kiebooms G, Cassiman JJ, Van den Berghe H. Risk perception after CF carrier testing and impact of the test result on reproductive decision making. Am J Med Genet 1997;69:422-428.

42. Gordon C, Walpole I, Zubrick SR, Bower C. Population screening for cystic fibrosis: knowledge and emotional consequences 18 months later. Am J Med Genet A 2003; 120:199-208.

43. Evers-Kiebooms G, Denayer L, Welkenhuysen M, Cassiman JJ, Van den Berghe H. A stigmatizing effect of the carrier status for cystic fibrosis? Clin Genet 1994;46:336-343. 


\section{Lakeman et al.}

44. Rowley PT, Lipkin M Jr, Fisher L. Screening and genetic counseling for beta-thalassemia trait in a population unselected for interest: comparison of three counseling methods. Am J Hum Genet 1984;36:677-689.

45. Zeesman S, Clow CL, Cartier L, Scriver CR. A private view of heterozygosity: eightyear follow-up study on carriers of the Tay-Sachs gene detected by high school screening in Montreal. Am J Med Genet 1984;18:769-778.

46. Henneman L, Poppelaars FA, Ten Kate LP. Evaluation of cystic fibrosis carrier screening programs according to genetic screening criteria. Genet Med 2002;4:241-249.

47. Lena-Russo D, Badens C, Aubinaud M, et al. Outcome of a school screening programme for carriers of haemoglobin disease. J Med Screen 2002;9:67-69.

48. Mitchell JJ, Capua A, Clow C, Scriver CR. Twenty-year outcome analysis of genetic screening programs for Tay-Sachs and beta-thalassemia disease carriers in high schools. Am J Hum Genet 1996;59:793-798.

49. Petrou M, Modell B, Shetty S, Khan M, Ward RH. Long-term effect of prospective detection of high genetic risk on couples' reproductive life: data for thalassaemia. Prenat Diagn 2000;20:469-474.

50. Poppelaars FA, Henneman L, Ader HJ, et al. Preconceptional cystic fibrosis carrier screening: attitudes and intentions of the target population. Genet Test 2004;8:80-89.

51. Marteau TM, Bekker H. The development of a six-item short-form of the state scale of the Spielberger State-Trait Anxiety Inventory (STAI). Br J Clin Psychol 1992;31: 301-306.

52. Van der Bij AK, De Weerd S, Cikot RJ, Steegers EA, Braspenning JC. Validation of the dutch short form of the state scale of the Spielberger State-Trait Anxiety Inventory: considerations for usage in screening outcomes. Community Genet 2003;6:8487.

53. Giordano PC, Dihal AA, Harteveld CL. Estimating the attitude of immigrants toward primary prevention of the hemoglobinopathies. Prenat Diagn 2005;25: 885-893.

54. Ahmed S, Green JM, Hewison J. Attitudes towards prenatal diagnosis and termination of pregnancy for thalassaemia in pregnant Pakistani women in the North of England. Prenat Diagn 2006;26:248-257.

55. Modell B, Harris R, Lane B, et al. Informed choice in genetic screening for thalassaemia during pregnancy: audit from a national confidential inquiry. $B M J 2000 ; 320$ 337-341.

56. Decruyenaere M, Evers-Kiebooms G, Denayer L, Welkenhuysen M. Uptake and impact of carrier testing for cystic fibrosis. A review and a theoretical framework about the role of knowledge, health beliefs and coping. Community Genet 1998;1: 23-35

57. National Institutes of Health. Genetic testing for cystic fibrosis. National Institutes of Health Consensus Development Conference Statement on genetic testing for cystic fibrosis. Arch Intern Med 1999;159:1529-1539.

58. Health Council of the Netherlands. 2003. Public awareness about genetics. The Hague, Health Council of the Netherlands; publication no. 2003/05. Available at: www.gr.nl.

59. Baars MJ, Henneman L, Ten Kate LP. Deficiency of knowledge of genetics and genetic tests among general practitioners, gynecologists, and pediatricians: a globa problem. Genet Med 2005;7:605-610.

60. Health Council of the Netherlands. 1994. Genetic screening. The Hague, Health Council of the Netherlands; publication no. 1994/22E. Available at: www.gr.nl.

61. Health Council of the Netherlands. 2007. Preconception care: a good beginning. 2007. The Hague, Health Council of the Netherlands; publication no. 2007/19. Available at: www.gr.nl. 